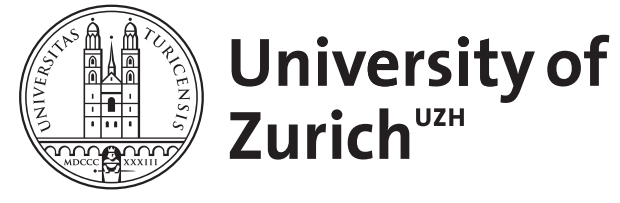
Archive

University of Zurich

University Library

Strickhofstrasse 39

CH-8057 Zurich

www.zora.uzh.ch

Year: 2010

\title{
Laparoscopic epilepsy surgery
}

Kistler, A D ; Schwarz, U ; Dalmau, J ; Rudiger, A

DOI: https://doi.org/10.1007/s00134-009-1657-3

Posted at the Zurich Open Repository and Archive, University of Zurich

ZORA URL: https://doi.org/10.5167/uzh-28030

Journal Article

Published Version

Originally published at:

Kistler, A D; Schwarz, U; Dalmau, J; Rudiger, A (2010). Laparoscopic epilepsy surgery. Intensive Care Medicine, 36(2):367-368.

DOI: https://doi.org/10.1007/s00134-009-1657-3 


\section{Andreas D. Kistler \\ Urs Schwarz \\ Josep Dalmau \\ Alain Rudiger}

\section{Laparoscopic epilepsy surgery}

Accepted: 13 August 2009

Published online: 18 September 2009

(C) Copyright jointly hold by Springer and ESICM 2009

\section{A 37-year-old woman became} disoriented, hallucinating and agitated after complaining of headache 2 weeks earlier. She was admitted to a psychiatric clinic, where she developed low-grade fever, gait disturbances and orofacial dyskinesias. Thus, she was referred to our hospital for further evaluation. Routine laboratory analyses and brain imaging showed no abnormalities. Lumbar puncture revealed mononuclear pleocytosis, but extensive microbiology testing showed no evidence of

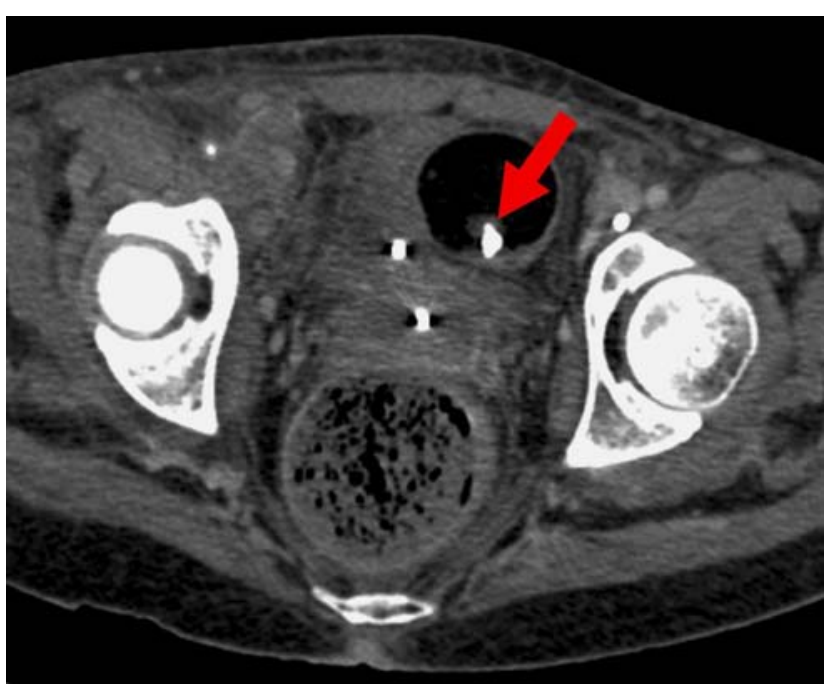

Fig. 1 Abdominal CT disclosed a cystic mass in the right pelvis containing a tooth (arrow) suggestive of mature ovarian teratoma microorganisms. Autoantibodies against the CNS antigens $\mathrm{Hu}, \mathrm{Ri}$, Yo, amphiphysin, CV2, Ta/Ma2, Ma and recoverin were undetectable. Ten developed generalized seizures.

Treatment with phenytoin and highdose midazolam was initiated, and the patient was transferred to the ICU for mechanical ventilation. Although repeated lumbar punctures documented a continuous drop in CSF cell count from 44 to 2 cells/ $\mu 1$ within a month, the patient remained in a mostly non-convulsive intermittent status epilepticus refractory to treatment with various antiepileptic drugs for nearly 2 months. She further developed severe hyperthermia, hypersalivation, tachycardia and episodes of bradycardia. Incidentally, a computed tomography of the abdomen revealed a mature ovarian teratoma (Fig. 1). Treatment with high-dose prednisolone and intravenous immunoglobulines was started. After cessation of seizures, the patient underwent laparoscopic teratoma removal. Histologic examination revealed the presence of neuronal tissue within the teratoma, and high titers of antibodies against NMDAreceptors were detected in the days after admission, the patient patient's CSF (Fig. 2). Midazolam was tapered after surgery, and the patient regained consciousness. One year later, she was able to resume work as a postman without any residual deficits.

The possible association of encephalitis with teratoma has been noted for a while (reviewed by Gultekin [1]), but only recent studies have identified an association of this syndrome with antibodies to the NMDA receptor $[2,3]$. These antibodies lead to reversible downregulation of hippocampal NMDA receptors through a non-cytotoxic mechanism [3]. They probably arise by autoimmunisation due to the expression of NMDA receptors in neuronal tissue within the teratoma [2] and might initially pass the bloodbrain barrier after its disruption by a precedent hit such as viral meningitis, as suggested by the CSF pleocytosis present in most patients. During the course of the disease, however, most patients exhibit local production of antibodies within the CNS as indicated by the higher antibody titers in CSF as compared to serum [3]. Of interest, nearly half of patients suffering from encephalitis associated with anti-NMDA-receptor antibodies have no detectable teratoma [3], suggesting alternative mechanisms of autoimmunization. The disease predominantly affects young women and is characterized by prominent psychiatric symptoms, dyskinesias, seizures, autonomic instability and central hypoventilation. Many patients display no abnormalities on neuroimaging studies, consistent with the antibody-mediated non-inflammatory nature of the disease [4]. Symptoms are mostly reversible upon immunotherapy and tumor removal, and patients without a detectable teratoma show more protracted symptoms and relapses, although they often recover [1]. Anti-NMDAreceptor encephalitis is probably more common than previously 


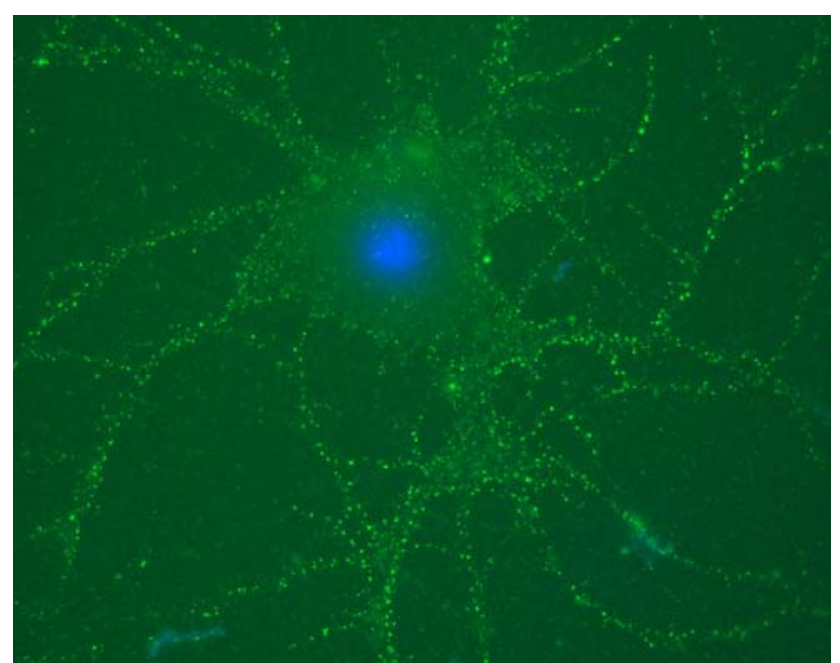

Fig. 2 Cultured rat hippocampal neurons were incubated with the patient's CSF revealing binding of autoantibodies to NMDA receptors (green dots) visualized by adding a fluorescence-labeled secondary antibody to human immunoglobulin

estimated and should be considered in any case of unexplained encephalitis, especially in young women.

\section{References}

1. Gultekin SH, Rosenfeld MR, Voltz R, Eichen J, Posner JB, Dalmau J (2000) Paraneoplastic limbic encephalitis: neurological symptoms, immunological findings and tumour association in 50 patients. Brain 123:1481-1494
3. Dalmau J, Gleichman AJ, Hughes EG, Rossi JE, Peng X, Lai M, Dessain SK, Rosenfeld MR, Balice-Gordon R, Lynch DR (2008) Anti-NMDA-receptor encephalitis: case series and analysis of the effects of antibodies. Lancet Neurol 7:1091-1098

4. Tonomura $\mathrm{Y}$, Kataoka H, Hara Y, Takamure M, Naba I, Kitauti T, Saito K, Ueno S (2007) Clinical analysis of paraneoplastic encephalitis associated with ovarian teratoma. J Neurooncol 84:287-292

A. D. Kistler · A. Rudiger ( $\bullet$ )

Department of Internal Medicine, University Hospital of Zurich, Raemistrasse 100, 8091 Zurich, Switzerland e-mail: alain.rudiger@usz.ch

Tel.: +41-44-2551111

Fax: +41-44-2553181

U. Schwarz

Department of Neurology,

University Hospital of Zurich,

Zurich, Switzerland Rossi JE, Voloschin A, Baehring JM, Shimazaki H, Koide R, King D, Mason W, Sansing LH, Dichter MA, Rosenfeld MR, Lynch DR (2007) Paraneoplastic anti- $N$-methyl-D-aspartate receptor encephalitis associated with ovarian

\section{J. Dalmau}

Department of Neurology,

University of Pennsylvania,

Philadelphia, USA 